John Carroll University

Carroll Collected

2019 Faculty Bibliography

Faculty Bibliographies Community Homepage

2019

\title{
To Link or Not to Link? Multiple Team Membership and Unit Performance
}

Eean R. Crawford

University of Iowa

Cody J. Reeves

Brigham Young University

Greg L. Stewart

University of Iowa

Stacy L. Astrove

John Carroll University, sastrove@jcu.edu

Follow this and additional works at: https://collected.jcu.edu/fac_bib_2019

Part of the Organizational Behavior and Theory Commons

\section{Recommended Citation}

Crawford, Eean R.; Reeves, Cody J.; Stewart, Greg L.; and Astrove, Stacy L., "To Link or Not to Link? Multiple Team Membership and Unit Performance" (2019). 2019 Faculty Bibliography. 39.

https://collected.jcu.edu/fac_bib_2019/39 


\title{
To Link or Not to Link? Multiple Team Membership and Unit Performance
}

\author{
Eean R. Crawford \\ U.S. Department of Veterans Affairs, Iowa City, Iowa, and \\ University of Iowa \\ Greg L. Stewart \\ U.S. Department of Veterans Affairs, Iowa City, Iowa, \\ and University of Iowa
}

\author{
Cody J. Reeves \\ U.S. Department of Veterans Affairs, Iowa City, Iowa, \\ and Brigham Young University \\ Stacy L. Astrove \\ U.S. Department of Veterans Affairs, Iowa City, Iowa, \\ and John Carroll University
}

\begin{abstract}
Multiple team membership is common in today's team-based organizations, but little is known about its relationship with collective effectiveness across teams. We adopted a microfoundations framework utilizing existing individual- and team-level research to develop a higher-level perspective on multiple team membership's relationship with performance of entire units of teams. We tested our predictions with data collected from 849 primary care units of the Veterans Health Administration serving over 4.2 million patients. In this context, we found multiple team membership is negatively associated with unit performance, and this negative relationship is exacerbated by task complexity.
\end{abstract}

Keywords: multiple team membership, unit performance, task complexity, archival measures

Individuals rarely work for a single team in contemporary organizations but instead have cross-cutting relationships with multiple groups (Espinosa, Cummings, Wilson, \& Pearce, 2003; Katz, Lazer, Arrow, \& Contractor, 2004; Maynard, Mathieu, Rapp, \& Gilson, 2012; O'Leary, Mortensen, \& Woolley, 2011). This structure of multiple team membership_defined as assigning members to work for more than one team simultaneously (O'Leary et al., 2011) — is adopted by organizations in the hopes of using human resources more efficiently and thereby increasing organizational effectiveness (Milgrom \& Roberts, 1992; Zika-Viktorsson, Sundström, \& Engwall, 2006). Despite as many as $95 \%$ of workers across a wide variety of industries reporting concurrent membership in more than one team (Martin \& Bal, 2015), the extent to which multiple team membership enhances organizational performance is not fully understood.

Tannenbaum, Mathieu, Salas, and Cohen's (2012) comprehensive review noted that new research is necessary to understand the implications of working in multiple teams across various levels of analysis, including individual well-being, team effectiveness, and collective effectiveness across teams. To date, research has not focused on collective effectiveness at higher levels, but studies at the individual and team levels have suggested that multiple team membership potentially has both benefits and harms. Benefits possibly accrue from more efficient work practices, greater utili- 
zation of time, increased access to external resources, and improved load balancing between teams (Cummings \& Haas, 2012; de Vries, Walter, Van der Vegt, \& Essens, 2014; Kc \& Terwiesch, 2009; O'Leary et al., 2011). However, harms can accumulate from fragmented attention, higher switching costs, increased strain, more lags and delays, reduced cohesion, and poorly developed routines and mental models within teams (Argote \& Todorova, 2007; de Vries et al., 2014; Lewis, Lange, \& Gillis, 2005; Mortensen, 2014; O'Leary et al., 2011; Pluut, Flestea, \& Curşeu, 2014; Staats, Gino, \& Pisano, 2010; Wilson, Goodman, \& Cronin, 2007; Zika-Viktorsson et al., 2006).

How these effects aggregate from the individual and team levels to combine with between-team effects to influence collective effectiveness across teams is not known. First, in discussing their development of the most comprehensive theory on the subject, O'Leary and colleagues (2011) acknowledged they did not address the dynamics of multiple team membership at levels above the team, and they called for research that does so. This is critically important because the unit-level consequences of multiple team membership reverberate beyond individuals and focal teams and because relationships will not necessarily be isomorphic across levels of analysis (Kozlowski \& Klein, 2000). Thus, it is not known how existing individual- and team-level theory about members' being assigned to multiple teams applies to entire units of teams. Second, given that optimal organizational structure is generally contingent on factors such as the environment and nature of work tasks (Burns \& Stalker, 1961; Johns, 2006; Kerr, 2015; Miller, Glick, Wang, \& Huber, 1991), answers to the question of whether multiple team membership's benefits to aggregate performance outweigh its harms must be contextually derived.

We address this gap in understanding with a unit-level study of multiple team membership and aggregate performance across teams. Consistent with prior unit-level research (Harter, Schmidt, \& Hayes, 2002; Hausknecht, Hiller, \& Vance, 2008; Hausknecht \& Trevor, 2011; Reilly, Nyberg, Maltarich, \& Weller, 2014), we conceptualized units as the standalone establishments of an entire company, organization, or enterprise. In our case we examined multiple team membership's relationship with performance among the 849 primary care units operating in standalone hospitals and clinics of the Veterans Health Administration (VHA). Each primary care unit had been divided into multiple care teams tasked with providing primary care for allocated patients.

Our study was motivated by recent suggestions from a number of scholars that investigations of a phenomenon begin by seeking to understand a problem experienced by organizations (Aguinis \& Vandenberg, 2014; Hambrick, 2007; Mathieu, 2016; Spector, 2017). We specifically began our investigation by observing the VHA struggle with the question of the extent to which nurses and support staff should be assigned to multiple teams within primary care units. Surprisingly, units varied greatly in the extent to which primary care team members were simultaneously members of other primary care teams in the same unit. Primary care unit leadership desired to understand whether sharing members across teams was beneficial for the collective performance of teams comprising the unit or whether it would be more beneficial for members to remain on single teams. Accordingly, we gathered and analyzed quantitative data to examine what effect multiple team membership was having on unit performance. We simultaneously searched the literature and developed a theoretical explanation of how multiple team membership dynamics at individual and team levels aggregate to affect unit performance. Our research efforts were thus initiated by observing an organizational problem that led to an iterative process of abduction wherein we simultaneously analyzed data and developed theory to understand and explain the higher-level effects of multiple team membership.

Our research makes three contributions. First, we provide evidence addressing the higher-level problem of whether members should be shared across teams. We provide the only empirical analysis to date capturing unit-level variation in team membership structure ranging from units where individuals are predominantly assigned to single, bounded teams to units where individuals are assigned to multiple interconnected teams with blurred boundaries. Second, we develop theory to explain when multiple team membership is beneficial or harmful at the unit level. Specifically, we adopted a microfoundations approach to extend previously published individual and team perspectives and to explain how multiple team membership relationships emerge into aggregate effects at a higher level. Third, we extend the theory we develop, going beyond the original organizational problem, to explore how task complexity moderates the relationship between multiple team membership and unit performance.

\section{Situating Multiple Team Membership in the Organizational Context}

O'Leary and colleagues (2011) stressed that, as a starting point, any examination of multiple team membership must closely consider the general context of the research setting. Johns (2006) explained that organizational context may be manifest in how organizations are configured to deal with work. Following these appeals to account for context, we first explain the VHA setting to illustrate our study-specific configuration of structure and tasks associated with sharing of team members. We then situate our study within a broader organizational structure perspective by contrasting our specific context with alternative configurationsparticularly multiteam systems - that represent different approaches for unit-level structuring of relationships between teams. Such explication of context allow us to illustrate not only how our general research question arose but also how our theoretical development fits in the larger framework of organizational structure and multiple team membership.

\section{The VHA Primary Care Team Context}

The VHA recently adopted a medical home model to efficiently provide ongoing primary patient care through proactive customization that considers the unique needs of each patient (Bodenheimer, Ghorob, Willard-Grace, \& Grumbach, 2014; Rosland et al., 2013). This patient-centered care delivery model is enacted through a team-based structure wherein teams composed of a primary care provider (e.g., doctor), a registered nurse care manager, a licensed practical nurse, and an administrative associate take responsibility for a panel of approximately 1,200 patients (American Academy of Family Physicians, 2008; Rosland et al., 2013). The four interdisciplinary roles were included to assure that required skill and knowledge to deliver primary care to the patient are contained and coordinated within the team, making it possible for patients to interact almost exclusively with their assigned 
teams. This structure reduces the need for coordination with other primary care doctors, nurses, and administrative associates outside the team (Bodenheimer et al., 2014).

Given the patient-centered medical home model's emphasis on assigning patients to small primary care teams with bounded membership, the VHA did not initially advocate for multiple team membership. However, approximately two and a half years after the team-based initiative began, analysis provided clear evidence of substantial variation in multiple team membership across primary care units. In particular, we used two-mode sociometric affiliation visualization techniques to illustrate unit-level multiple team membership_-defined as the "average number of team memberships held by individual members" at the given point in time (O'Leary, Woolley, \& Mortensen, 2012, p. 147). Two illustrative examples are shown in Figure 1. As can be seen, although the overall staff numbers are not meaningfully different across the two primary care units, the unit shown on the left has limited sharing of team members, whereas the unit on the right has extensive sharing. Such variation across units was surprising, because the tenets of the patient-centered medical home model recommend primary care service delivery through a small team of highly coordinated members rather than through connections between teams. Because multiple team membership can direct attention to between-team coordination at the expense of within-team coordination (O'Leary et al., 2011), we assumed that multiple team membership would be harmful in this primary care setting. However, we also began searching the literature to develop theory concerning the unit-level effects of multiple team membership as a way of extending current theory at the individual and team levels of analysis.

\section{Situating the VHA Within General Approaches to Team-Based Structure}

The VHA setting and our associated unit-level theory development can be situated via Sinha and Van de Ven's (2005) principle of hierarchical decomposition. This principle asserts that coordination needs should be bounded in the smallest grouping possible and then move to higher-order groupings until coordination needs have been adequately addressed. This notion is consistent with Thompson's (1967) logic of organizational design, which asserts that organizations maximize efficiency and effectiveness by segmenting tasks with the highest need for coordination into the smallest local grouping possible, with general autonomy granted to the local groupings to the greatest extent allowable within the organizational system. When coordination needs cannot be contained within first-order groupings (because tasks may be too large or complex), organizations will use a second-order grouping to extend coordination beyond the initial groupings. Coordination needs not adequately handled by second-order groupings create the need for third-order groupings to handle aspects of coordination beyond the scope of second-order groupings, and so on. Thus, in accordance with hierarchical decomposition, team-based organizational structure is optimized by first grouping as many interdependent tasks as possible within teams and allowing those teams the greatest possible autonomy. Tasks that cannot be coordinated within teams should then be coordinated between teams.

The underlying objective of the VHA's hierarchical decomposition of primary care into patient-centered medical homes was to replace a previous structure where several providers coordinated primary care across multiple nurses and administrative associates. The new structure would be a team-based structure in which small teams of highly specialized and interdependent members coordinate care within the team without needing to coordinate care between other similarly structured primary care teams. This is a common team-based organizational configuration in which functionally equivalent and operationally independent teams do not have higher-order coordination needs beyond a general interest in success of the organization (O'Leary et al., 2012; see also Cohen \& Bailey, 1997, and Sundstrom, McIntyre, Halfhill, \& Richards, 2000 , for an extensive listing of team studies in organizations of

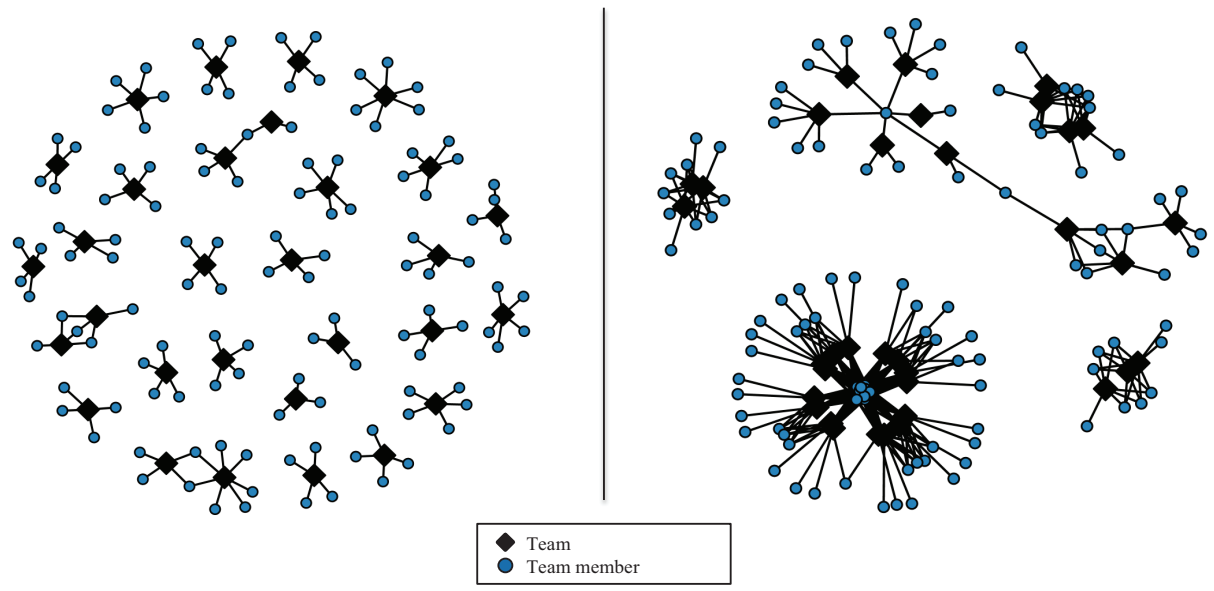

Figure 1. Sociometric visualization of team membership structure in two Veterans Health Administration primary care units. Teams are represented as diamonds, team members are represented as circles, and assignments to teams are represented with lines connecting circles to diamonds. Individuals' number of team memberships is visualized simply as the number of diamonds to which their circles are connected. See the online article for the color version of this figure. 
this type across a wide range of service and manufacturing industries). The extent to which multiple team membership occurs in these contexts is uncertain, but initial evidence has suggested it is pervasive. For example, using a large sample drawn from a wide range of industries and professional occupations in this context, O'Leary and colleagues (2012) discovered that $81 \%$ of team members worked on more than one team at a time, with it not uncommon that individuals were members of as many as five or more teams $(M=2.75, S D=3.77)$.

The VHA's hierarchically independent teams are distinct from another type of hierarchical decomposition resulting in what are known as multiteam systems. The component teams of a multiteam system are highly interdependent and work in a tightly coupled fashion to resolve higher-order coordination needs in pursuit of one or more superordinate goals (Mathieu, Luciano, \& DeChurch, 2018; Mathieu, Marks, \& Zaccaro, 2001; Zaccaro, Marks, \& DeChurch, 2012). Multiple team membership has been present in previous multiteam system studies and viewed as a useful mechanism for facilitating coordination between teams (e.g., Davison, Hollenbeck, Barnes, Sleesman, \& Ilgen, 2012; Firth, Hollenbeck, Miles, Ilgen, \& Barnes, 2015; Lanaj, Hollenbeck, Ilgen, Barnes, \& Harmon, 2013). However, multiple team membership is typically held constant in any one study's design and usually restricted to a limited number of boundary spanners (Ancona, 1990; Ancona \& Caldwell, 1992), who are members of at most two teams. As such, the question of how multiple team membership relates to the effectiveness of multiteam systems has yet to be addressed and is beyond the scope of this investigation. However, a pertinent insight one can derive from the multiteam systems literature is that the benefits of between-team coordination relative to those of within-team coordination for system performance are contingent on the intensity of the coordination needs between teams (Lanaj et al., 2013; Marks, DeChurch, Mathieu, Panzer, \& Alonso, 2005). Given that multiple team membership can be a mechanism for facilitating between-team coordination, greater sharing of members may be beneficial in contexts where the coordination of highly interdependent teams must be dealt with at the unit level. However, greater sharing of members may be detrimental in contexts where there is little need to coordinate between hierarchically independent teams. The latter context is represented in our unitlevel investigation.

In sum, our theoretical development and empirical investigation borrows insight from multiteam systems research where sharing of team members is viewed as a potentially useful mechanism for facilitating coordination among teams. Within the context of the hierarchically independent teams of the primary care units of the VHA, the potential unit-level benefits of multiple team membership are less clear. In the next section, we draw on a microfoundations approach to extend individual and team level perspectives to suggest when the potential benefits of multiple team membership to between-team coordination are offset by decrements in within-team coordination that in turn harm unit-level performance.

\section{Microfoundational Effects of Multiple Team Membership on Units of Hierarchically Independent Teams}

Microfoundations scholars have observed that the explanation of collective outcomes is often best accomplished by examining their origins in terms of lower level factors and social interaction (Barney \& Felin, 2013). This "microfoundations as a levels argument" suggests that the proximate causes of a phenomenon (or explanations of an outcome) are located at a level of analysis lower than that of the phenomenon itself (Felin, Foss, \& Ployhart, 2015, p. 586). In accordance with this notion, we examined the effects of multiple team membership on unit performance by considering how its effects at the individual and team levels emerge in a higher-level effect that represents phenomena at multiple levels. Such a notion of emergence is consistent with calls from both microfoundations and teams researchers to specify theoretically how it is that the interactions of individuals and teams at lower levels lead to collective outcomes that are not necessarily reducible to the individuals and teams themselves (Barney \& Felin, 2013; Kozlowski \& Klein, 2000).

\section{Individual Level: Time Efficiency, Context Switching, and the Role of Slack}

A crucial issue associated with multiple team membership at the individual level of analysis is the potential tradeoff between the benefits of efficiency in time usage through load balancing and the costs of decreased focus from context switching. On the benefit side, multiple team membership can improve time utilization because an individual waiting for a response from a coworker about one project can continue to work on a project for a different team. Being on more than one team gives an individual the opportunity to offset the ebbs of one team's work with the flows of another team's work (O'Leary et al., 2011). Multiple team membership also incentivizes individuals to adopt more efficient work practices by recognizing that their time available to work for any one team is limited.

On the cost side, however, multiple team membership impairs individual focus and fragments attention as individuals switch between team contexts. Individuals use significant time and effort to overcome the attention residues from prior contexts; reengage in the people, roles, issues, and operations of the current context; catch up on work done in their absence; shift between teamspecific routines; and physically relocate between team settings (Leroy, 2009; Mark, Gonzalez, \& Harris, 2005; O'Leary et al., 2012). These additional burdens can accumulate into a great deal of overload and role conflict for individuals, especially as the number of team contexts grows. Even among functionally equivalent teams, each team still constitutes its own domain with unique personalities, clients, and shared meanings (Schultz, 1991). O'Leary and colleagues (2012, p. 148) rightly pointed out that "though any two teams can be more or less similar in their tasks, technologies, roles, locations, routines, and symbolic meanings, other things being equal, the more teams one is on, the more context switching one will do."

A critical factor determining the relative higher-level benefits and harms of switching for individuals is the existence of slack time in the unit's production schedule. The portended benefits of individuals' switching from team to team depend on lulls existing in the work demands of discrete teams. If little slack exists because of high work demands in discrete teams, the individual-level costs of attention fragmentation and context switching accrue without the benefits of workload balancing such that there is a potentially negative unit-level effect. In the context of VHA primary care units, slack time in team members' schedules is rare. Almost all 
teams have their daily schedules filled with appointments from their own panel of up to 1,200 patients, such that there is very little time when team members are not directly consulting with patients or each other. Indeed, in a prior survey, most members of primary care teams reported relatively high levels of work overload (Solimeo et al., 2013). Ongoing workloads within discrete teams are therefore sufficiently high that little aggregate efficiency is gained by individuals' balancing work across multiple teams. The collective cost of individuals' switching their efforts among teams is likely greater than the collective benefit, suggesting that the unit-level effect of multiple team membership flowing from individual-level tradeoffs associated with switching will be negative in organizations such as the VHA, where teams have little slack in their production schedules.

\section{Team Level: Learning, Cohesion, and the Role of Resource Sufficiency}

At the team level of analysis, multiple team membership creates a potential tradeoff amid the benefits of improved team learning through between-team collaboration and the costs of within-team cohesion and shared cognition through misalignment of members' work time. On the benefit side, multiple team membership enables knowledge search for noncodifiable information (Hansen, 1999) as members spend time with other teams. The uniqueness and diversity of team members' information also increases as members have more unshared experiences outside the team (O'Leary et al., 2012). Time spent on different teams can also help members resolve uncertainties in the work environment by providing access to support and assistance from external members (de Vries et al., 2014).

However, multiple team membership creates difficulties for members to find overlapping time when the team can work together without members' engaging in another team's work. This is problematic because learning requires not only exposure to new information but also shared experience to process and integrate that information (Argote \& Todorova, 2007). Splitting time across teams limits the shared exposure and interaction necessary for discrete teams to become familiar with and generalize teamencoded roles and routines (Lewis et al., 2005; Staats et al., 2010). This can create a lack of clarity regarding who belongs on a team and inhibits transactive memory system development within the team (Mortensen, 2014). With few overlapping schedules, members may adjust their work structure to carry out more of their work as independent individuals (O'Leary et al., 2012), thereby working as groups in name only, or what Hackman (1987, p. 322) referred to as "co-acting groups," resulting in decreased social cohesion among team members (Maznevski \& Chudoba, 2000).

A critical factor determining the higher-level benefits and harms of the tradeoff concerning within-team coordination and cognition and between-team learning and cognition is the extent to which the knowledge and resources needed to accomplish tasks are selfcontained within discrete teams. If a team is equipped with sufficient knowledge, skills, resources, and personnel to accomplish a task, then external information and resources generated through multiple team membership are likely to be redundant. Yet costs associated with decreased social cohesion, poor cognition, and lack of coordination within teams continue to accrue within each team, such that there is a potentially cumulative negative unit-level effect. As described earlier, the VHA primary care teams were designed such that each team is composed of members whose specialized skills and knowledge combine to provide all necessary expertise to deliver ongoing primary care for their patients, and existing staffing levels were sufficient to allow such a design. This suggests that collaborating within the team (e.g., meeting often to discuss patients' health care goals and needs; making plans for how to accomplish those goals) is more critical for unit-level effectiveness than is coordination with other teams that provide little in the way of additional knowledge.

Based on the microfoundations as a levels concept, both the individual-level effect of switching and the combined within- and between-team effects of coordination are expected to operate such that multiple team membership corresponds negatively with unitlevel performance in the context of this study. These arguments make it clear that the division of work within teams does not simply sum to create effects at the unit level of analysis. Rather, the need to coordinate efforts within a team makes it so that assigning a pool of individuals to multiple teams potentially creates a total work effort of coordination that is greater than if individuals had each been assigned to a single team. It is a tenuous assumption that individuals who divide their time between teams can divide their responsibility and coordination effort for those teams proportionately. Rather, each individual must build and maintain working relationships and coordination processes with the personnel and clients of every team. As a result, multiple team membership creates aggregate work efforts that are greater than they would be had those contributions been focused within single teams. Instead of achieving efficiency gains, multiple team membership creates inefficiencies through duplication of effort that is most harmful in settings such as the VHA, where the principle of hierarchical decomposition can be followed to structure work that can be coordinated within hierarchically independent teams rather than through between-team coordination. Thus, within the specific context of units of hierarchically independent teams with both limited slack time and negligible need for between-team coordination, we expect multiple team membership's costs at the individual and team levels to aggregate to a greater extent than do their benefits to create an overall negative effect of multiple team membership on unit performance.

Hypothesis 1: In units of hierarchically independent teams, multiple team membership will be negatively associated with unit performance.

\section{Moderating Role of Task Complexity}

Team scholars have repeatedly stressed that the nature of the task, particularly the extent of the task's complexity, alters the suitability of different compositional arrangements of team members (Hollenbeck, Beersma, \& Schouten, 2012; Kozlowski \& Ilgen, 2006; Mathieu, Hollenbeck, van Knippenberg, \& Ilgen, 2017; McGrath, 1984). Task complexity has also been long considered a major factor determining the effectiveness of various forms of organizational structure (March \& Simon, 1958; Tushman \& Nadler, 1978; Van de Ven \& Delbecq, 1974; Van de Ven, Delbecq, \& Koenig, 1976). The prominence of task complexity in the literature and its pertinence to our organizational setting led us to the development of an additional hypothesis that multiple team 
membership's negative association with unit performance varies depending on task complexity. Specifically, we expect multiple team membership's negative relationship with primary care unit performance to be exacerbated as task complexity-indexed by the average complexity of patient medical conditions in a unitincreases.

Task complexity creates greater demands on team member effort and attention by multiplying information cues and increasing the perceptual and information processing requirements necessary to make valid judgments (Wood, 1986). Increased complexity also intensifies the need for ongoing mutual adjustment through enhanced sequencing and timing while simultaneously heightening the unpredictability of inputs, desired outcomes, and production process (Gladstein, 1984; Manz \& Stewart, 1997; Thompson, 1967; Van de Ven et al., 1976). Because the principle of hierarchical decomposition advocates that coordination take place within the smallest grouping possible, and because multiple team membership interferes with information processing, mutual adjustment, and adaptability within teams (O'Leary et al., 2012), the negative relationship between multiple team membership and unit performance is expected to be exacerbated in conditions of greater task complexity.

The accentuating negative effect of multiple team membership associated with complexity is specifically illustrated in the medical context where greater task complexity occurs as patients have a greater number of multifaceted, complicated medical conditions such as hypertension, diabetes, and heart disease, among others (Islam, Weir, \& Del Fiol, 2016). Compared to providing care for relatively healthy patients, providing effective care for more complex patients necessitates expanded interaction and the development of more customized treatment plans, which in turn intensify the workload and thereby increase the likelihood of accruing costs from switching attention and focus between teams. Complex patients are also more different from each other, meaning that they have more "degrees of difference," which, as O'Leary and colleagues (2012, p. 148) noted, make it more difficult to successfully switch between tasks and teams.

Caring for complex patients also frequently necessitates triage to assess the most pressing needs. Only after prioritizing acute needs can team members develop a plan of action. The plan is most likely to succeed if nurses and administrative associates are available to provide details about patient compliance with previous instructions, describe family and caregiver support that they have observed, and account for possible interactions with other medications that might be needed to treat other conditions. This coordination becomes more difficult as multiple team membership fractures these team members' common availability (O'Leary et al., 2012). In contrast to care that can be planned and standardized for relatively healthy patients, care for patients with complex conditions requires extensive adaptation and mutual ongoing coordination among team members.

In sum, increased information processing, mutual adjustment, and adaptation necessitated by complexity are likely best facilitated in focused teams whose members are with the team full time. We thus expect the harm of multiple team membership to unit performance to increase in conditions of greater task complexity.

Hypothesis 2: The negative relationship between multiple team membership and unit performance in units of hierarchi- cally independent teams will be exacerbated as task complexity increases.

\section{Method}

\section{Study Setting}

Our study encompassed the entire population of 849 VHA primary care units (i.e., hospitals and clinics) located in the United States serving over four million patients $(4,890$ patients per unit on average). The VHA's primary care units operate in a relatively independent manner and report unit-level performance metrics. Primary care covers prevention and treatment of common illnesses, identifying and managing patient needs, screening for and assessing health risks, and educating patients regarding conditions and medications (National Committee for Quality Assurance, 2013). This study was conducted under the approval of the University of Iowa Human Subjects Office/Institutional Review Board and the Iowa City Veteran Affairs Research and Development Committee with protocol title "Evaluation of VA Patient Aligned Care Teams (PACT)" and Protocol No. 201012763.

\section{Measures}

Multiple team membership. We operationalized multiple team membership at the unit level as the average number of team memberships per person in each primary care unit. We first collected each unit's team membership report and created a count of the number of teams to which each individual primary care employee was assigned. We then averaged individual employees' numbers of team memberships to the unit level. Accordingly, the measure of team membership at the unit level can be interpreted as the average number of teams to which individuals within a unit are assigned. Units in which individuals are each assigned to one team and only one team have an average number of team memberships of one.

Task complexity. We operationalized task complexity at the unit level with a measure of patient case complexity commonly used in both medical research and medical practice - the Diagnostic Cost Group average. This is a standardized risk adjustment measure in health care that utilizes patient diagnoses, demographic information, and prior health claims to assign patients to risk groups based on the expected resource needs for their conditions. As Pope et al. (2000) explained, patients are assigned to diagnostic groups based on medical conditions such as asthma, renal failure, attention deficit disorder, tuberculosis, congestive heart failure, depression, and HIV/AIDS, among others. Next, to compare these groups on a common metric (as opposed to treating membership in each group as its own categorical variable), the measure accounts for the estimated need for health care resources and services (in dollars) associated with the condition combinations of each patient, with more complex patients' being associated with higher dollar amounts. The resulting dollar value is compared to the estimated amount incurred by the average Medicare patient, resulting in a final ratio value. A patient case complexity score of 1.0 represents a patient whose medical conditions equate to those of the average Medicare patient, with scores greater than 1.0 representing more complex patients and scores less than 1.0 representing less complex patients. Patient case complexity scores were averaged at the 
unit level. As scholars have pointed out, this patient complexity measure was "originally designed to predict cost of expected care but has been validated to measure medical complexity within the VHA population" (P. Morgan et al., 2017, p. 5; see also Ellis \& Ash, 1995; Maciejewski et al., 2005).

Unit performance. A main goal of primary care services is to provide timely access to high-quality proactive and preventative primary care such that patients will rarely default to emergency departments for routine treatment (Flores-Mateo, Violan-Fors, Carrillo-Santisteve, Peiró, \& Argimon, 2012; S. R. Morgan, Chang, Alqatari, \& Pines, 2013). According to nationally representative data on ambulatory care visits to hospital emergency departments in the United States, an estimated 55\%-62\% of emergency department visits occur for nonurgent ailments that could be treated effectively in a primary care setting (McCaig, 1994; Rui \& Kang, 2015). After adjusting for measures of patient medical need, demographic characteristics, and other covariates, a major explanatory factor for emergency department use is the quality of primary care services, including access to timely appointments and continuity of provided care, as has been shown in studies of the elderly (Ionescu-Ittu et al., 2007), children (Brousseau et al., 2007), and nonelderly adults (Lowe et al., 2005).

Because emergency care services serve as a safety net for patients when primary care is inadequate, the utilization of these services can be considered a key indicator of the failure of primary care. In addition, health practitioners and managers are concerned about emergency department overuse because of its higher cost relative to primary care, adverse outcomes from lack of continuity and follow-up with primary care, diversion of resources from lifethreatening situations to minor problems, and hospital overload that becomes a source of staff frustration and patient dissatisfaction (Flores-Mateo et al., 2012). As such, we operationalized unit performance with a reverse indicator: the number of emergency department visits made by patients assigned to the unit in the prior 12 months. This number of emergency department visits includes both emergency rooms and urgent care encounters; is a standard metric that is tracked and reported by each VHA primary care unit; and is interpreted by VHA leaders as a key indicator of each unit's primary care service performance, where higher numbers of emergency department visits are indicative of worse primary care unit performance.

Model covariates. To account for the possibility that the relationship between the number of team memberships and emergency department use is actually determined by variation in staffing resources across primary care units, we accounted for staffing levels as a covariate in our models in two ways. First, we accounted for each unit's staff-to-provider ratio, or the ratio of support staff full-time equivalents to primary-care provider fulltime equivalents. The number of primary care providers allocated to each unit is a function of the number of patients served (one provider per 1,200 patients). The number of staff needed to complete each provider's care team is three (staff include the registered nurse care manager, licensed practical nurse, and administrative associate). Accordingly, the VHA's target staff-to-provider ratio for each primary care unit is three staff to one provider. Thus, given a size of a patient population (and corresponding number of providers), the staff-to-provider ratio indicates the total staffing hours available within a primary care unit. By accounting for the staff-to-provider ratio, we effectively captured the degree to which relationships are driven by units being over- or understaffed based on the number of hours of staff time available per week.

A second way we accounted for staffing levels was by including the average team size in each unit, calculated as the number of distinct people on each team, averaged to the unit level. It is possible for units to have identical staff-to-provider ratios but differing team sizes, such as when a unit uses multiple part-time staff that sum to one full-time equivalent on a team. This creates a larger number of team members compared to a unit that uses a single person as the full-time staff equivalent per team. Thus, staff-to-provider ratio accounts for staffing levels in terms of the number of available staff hours, whereas average team size accounts for staffing levels based on the head count of distinct individuals. The inclusion of both covariates helped rule out the availability of staffing resources as an alternative explanation and allowed us to isolate the effect of multiple team membership on unit performance holding staffing resources constant.

Another alternative explanation for differences in emergency department use might simply be the geographic location of the primary care unit. We addressed this in two ways. First, the 849 primary care units are grouped by the VHA into 21 larger regions corresponding to geographic areas of the United States. We explored the need to account for geographic region as a covariate, but aggregation statistics suggested that geographic region did not explain meaningful variance in emergency department use (intraclass coefficient[1] $=.01$ ). Therefore, we did not account for geographic region in our final analysis. However, as a robustness check, we ran each model including a dummy-coded fixed effect for the geographic region of each primary care unit. Substantive model results were unchanged.

Second, because emergency department use may systematically vary between urban and rural locations due to differing patient population densities or distances to the primary care unit, we accounted for environmental differences within geographic regions by modeling whether a primary care unit was located in an urban area as opposed to a rural area. Our dummy-code for urban/rural location (where urban $=1$, rural $=0$ ) was taken from the VHA's previous classification of each primary care unit based on the federal Rural-Urban Commuting Area code associated with the zip code of each primary care unit's physical location (Guagliardo et al., 2013; Johnson et al., 2018).

\section{Data Analysis}

We conducted all analyses using R Version 3.3.1 (R Core Team, 2016). Our dependent variable of emergency department visits is a count variable reflecting the number of occurrences of an event in a fixed period of time that can take on only nonnegative integer values. Because its distribution departs from normality and resembles that of a power law (i.e., a large proportion of counts cluster near the low end of the distribution and a small proportion of counts extend out in a long, right-skewed tail; Joo, Aguinis, \& Bradley, 2017), standard ordinary least squares regression is not appropriate for our analysis, because it may produce biased results (Gardner, Mulvey, \& Shaw, 1995). The Poisson family of regression models is more appropriate for analysis of count data because it maintains maximal statistical power while maintaining the proper Type I error rate (Coxe, West, \& Aiken, 2009; Long, 1997). However, the standard Poisson model requires an assumption that 
the conditional mean and variance of the distribution be equal, a condition known as equidispersion. When the variance is larger than the mean, the distribution exhibits overdispersion. If overdispersion is not accounted for in Poisson regression, estimates of standard errors will be too small, resulting in biased tests of significance and artificially inflated Type I error rates (Coxe et al., 2009). The negative binomial model is a more general form of standard Poisson that accounts for overdispersion. Interpretation of regression coefficients is identical to that of standard Poisson, but the negative binomial provides conservative standard errors. Because the distribution of emergency department visits in our data indeed exhibited evidence of overdispersion, we tested all hypotheses using negative binomial regression.

A challenge with predicting counts of emergency department visits is that their likelihood depends on the size of the patient population. Primary care units with larger patient populations will naturally have greater opportunity for patients to visit the emergency department than will primary care units with smaller populations. A count of 1,000 emergency department visits from a patient population of 10,000 is meaningfully different from a count of 1,000 visits from a patient population of 2,000. When the opportunity of an event occurring is not the same for each unit, it is necessary to adjust for the amount of exposure each unit faces. This can be done by introducing the exposure as the denominator in the $\log$ of the outcome count (i.e., ln [count/exposure]). However, because the Poisson family of regression models apply to only discrete outcome counts, the exposure in the denominator must be moved to the predictor side of the equation as $\ln$ (exposure) with a fixed coefficient equal to 1 using the algebraic properties of natural logarithms (Allison, 1999; Coxe et al., 2009; Long, 1997). This natural $\log$ of the exposure variable is known as an offset. It is differentiated from the other independent variables in that its coefficient (fixed at 1) is not presented or tested for significance, and it allows the coefficients of the remaining independent variables to be interpreted as effects on counts per unit of exposure. Accordingly, we included the natural log of the number of patients for each primary care unit as our offset variable, with the remaining coefficients interpreted as the percentage of change in per capita emergency department visits expected from a 1-unit increase in the independent variable. ${ }^{1}$

\section{Data Overlap Acknowledgment}

We acknowledge that a very small amount of data in the present research overlaps with that published in Stewart, Astrove, Reeves, Crawford, and Solimeo (2017). Specifically, the articles have two variables in common: (1) patient case complexity operationalized via the Diagnostic Cost Group average and (2) the number of patients, which simply reflects the size of the patient population. The number of cases that overlap with these variables is small because the two articles address different questions at different levels of analysis. The data in Stewart et al. (2017) were obtained from 224 teams and are analyzed at the team level to examine how and why team leaders' status affects their effectiveness of implementing a team-based empowerment intervention. The data in the present research were obtained from 5,291 teams arrayed across 849 independent primary care units and are analyzed at the unit level to examine the effects of multiple team membership on unit performance.

\section{Results}

Means, standard deviations, and bivariate correlations between all study variables are shown in Table 1 . As might be expected, we found a positive relationship between the number of emergency department visits and patient case complexity $(r=.25, p<.05)$, indicating that patients with more complex health conditions tend to utilize emergency department services more frequently. In addition, we found that a unit's number of patients $(r=.84, p<.05)$ and its urban location $(r=.29, p<.05)$ were positively associated with the number of emergency department visits, indicating the importance of accounting for exposure effects and geographic location in our models. Table 2 contains the results from negative binomial regression analyses. We first ran a covariates-only model predicting the number of emergency department visits per unit adjusted for the size of the patient population and accounting for the primary care unit's staff-to-provider ratio, average primary care team size, urban-rural location, and average patient case complexity. Results indicated that the inclusion of these explanatory variables significantly improved model fit over the null model $($ L. Ratio $=2,075.25, p<.05)$.

Our second model added the units' average number of team memberships while accounting for all covariates. Results show that the average number of team memberships was positively associated with emergency department visits $(b=.04, p<.05)$. Inclusion of primary care units' average number of team memberships as a predictor of the number of emergency department visits resulted in a statistically significant increase in model fit over the covariate-only model $($ L. Ratio $=4.32, p<.05)$. As primary care unit caregivers belong to an increasing number of teams, primary care unit performance is worse because patients generally seek more care through the emergency department. This provides support for Hypothesis 1.

Prior theory (O'Leary et al., 2011) and at least one empirical study at the team level of analysis (Bertolotti, Mattarelli, Vignoli, \& Macrì, 2015) suggest that benefits and harms of multiple team membership combine in a curvilinear fashion such that moderate levels of multiple team membership are most desirable for any focal team. We thus investigated the potential for a curvilinear effect at the unit level by including the squared average number of team memberships as an additional predictor of emergency department visits. Results do not provide support for a unit-level curvilinear relationship $(b=.00, n s)$, because adding the squared term did not significantly improve model fit over the first-order model (L.Ratio $=.06, n s$ ).

We next tested the interaction between primary care units' average number of team memberships and patient case complexity on the number of emergency department visits. We found a significant positive interaction between the number of team member-

\footnotetext{
${ }^{1}$ We examined the reasonableness of the offset designation (with a fixed coefficient of 1) by estimating each model with the natural $\log$ of the number of patients included as a freely estimated covariate. In all models, the freely estimated coefficient for $\log$ (number of patients) was close to 1.0 $($ range $=1.11-1.12)$, supporting the appropriateness of an offset designation. Furthermore, all substantive findings were unchanged, though coefficients for the main and interaction effects were slightly larger when the $\log$ (number of patients) coefficient was freely estimated. We present the more conservative results from offset-designated models here. Results from models freely estimating the $\log$ (number of patients) coefficient are available from Eean R. Crawford upon request.
} 
Table 1

Means, Standard Deviations, and Correlations Among Study Variables

\begin{tabular}{|c|c|c|c|c|c|c|c|c|}
\hline Variable & $M$ & $S D$ & 1 & 2 & 3 & 4 & 5 & 6 \\
\hline 1. No. of patients & $4,890.23$ & $5,208.45$ & - & & & & & \\
\hline 2. Staff-to-provider ratio & 3.17 & 1.04 & .04 & - & & & & \\
\hline 3. Average team size & 4.02 & 1.27 & .01 & .06 & - & & & \\
\hline 4. Urban-rural location ${ }^{\mathrm{a}}$ & .56 & .50 & $.43^{*}$ & -.04 & .01 & - & & \\
\hline 5. Patient case complexity & .58 & .21 & $.12 *$ & -.04 & -.01 & $.08^{*}$ & - & \\
\hline 6. Average no. of team memberships & 1.44 & .74 & -.06 & $-.17^{*}$ & $.41^{*}$ & .00 & .01 & - \\
\hline 7. No. of emergency department visits & $1,748.65$ & $3,217.52$ & $.84^{*}$ & .05 & .01 & $.29^{*}$ & $.25^{*}$ & -.02 \\
\hline
\end{tabular}

Note. $\quad N=849$ organizations.

${ }^{\text {a }}$ Coded as 1 (urban) and 0 (rural).

${ }^{*} p<.05$

ships and patient case complexity $(b=.06, p<.05)$, such that the positive association between the number of team memberships and emergency department visits is stronger in units with more complex patients. This interaction model demonstrated improved model fit over the first-order main effect model (L.Ratio $=5.84$, $p<.05)$. This provides support for Hypothesis 2, in which we expected the relationship between multiple team membership and primary care unit performance to be even worse for units whose patients have more complex health needs. As the number of team memberships on average increases in these units, more complex patients are even more likely to visit the emergency department.

We conducted simple slope tests using the indirect method recommended by Dawson (2014) to examine the significance of the unit-level multiple team membership effect at values of patient case complexity one standard deviation above and below the mean (patient case complexity was centered previously to remove nonessential multicollinearity). Simple slope tests confirmed that the strongest association between multiple team membership and emergency department visits is found at high levels of patient case complexity $\left(b_{\text {high complexity }}=.11, p<.05\right)$, with a smaller but positive association at mean levels of patient case complex- ity $\left(b_{\text {mean complexity }}=.05, p<.05\right)$ and a nonsignificant association at low levels of patient case complexity $\left(b_{\text {low complexity }}=-.02\right.$, $n s)$. The interaction is illustrated in Figure 2, which plots the relationships between the number of team memberships and number of emergency department visits at the mean and at one standard deviation above and below the mean of patient case complexity.

To illustrate the practicality of effects, we exponentiated the sum of our model coefficients multiplied by relevant variable values to get estimated numbers of emergency department visits at varying levels of multiple team membership and patient case complexity. In all cases, we held the number of patients, staffing levels, and unit location constant at their means. For a unit with average patient case complexity, our model estimated that the predicted emergency department use when all caregivers are assigned to only one team is approximately 1,238 visits per year. An increase of just one team membership per person is expected to result in approximately 87 additional emergency department visits per year (a 7\% increase). An increase of two team memberships per person is expected to result in approximately 179 additional emergency department visits per year (a 14\% increase). An increase to five team memberships per person, which is within our

Table 2

Negative Binomial Regression Results for Number of Emergency Department Visits per Patient

\begin{tabular}{|c|c|c|c|c|c|c|c|c|}
\hline \multirow[b]{2}{*}{ Variable } & \multicolumn{2}{|c|}{$\begin{array}{c}\text { Covariates } \\
\text { model }\end{array}$} & \multicolumn{2}{|c|}{ Linear model } & \multicolumn{2}{|c|}{$\begin{array}{l}\text { Curvilinear } \\
\text { model }\end{array}$} & \multicolumn{2}{|c|}{$\begin{array}{l}\text { Interaction } \\
\text { model }\end{array}$} \\
\hline & $b$ & $S E$ & $b$ & $S E$ & $b$ & $S E$ & $b$ & $S E$ \\
\hline Intercept & $-1.45^{*}$ & .03 & $-1.45^{*}$ & .03 & $-1.46^{*}$ & .03 & $-1.45^{*}$ & .03 \\
\hline Staff-to-provider ratio ${ }^{a}$ & $.06^{*}$ & .02 & $.07^{*}$ & .02 & $.07^{*}$ & .02 & $.07^{*}$ & .02 \\
\hline Avg. team size ${ }^{\mathrm{a}}$ & -.03 & .02 & $-.05^{*}$ & .02 & $-.05^{*}$ & .02 & $-.05^{*}$ & .02 \\
\hline Urban-rural location $^{\mathrm{b}}$ & $.19^{*}$ & .03 & $.19^{*}$ & .03 & $.19^{*}$ & .03 & $.19^{*}$ & .03 \\
\hline Patient case complexity ${ }^{\mathrm{a}}$ & $.54^{*}$ & .02 & $.54^{*}$ & .02 & $.54^{*}$ & .02 & $.53^{*}$ & .02 \\
\hline Avg. no. of team memberships ${ }^{a}$ & & & $.04^{*}$ & .02 & .03 & .03 & $.05^{*}$ & .02 \\
\hline Average no. of team memberships squared & & & & & .00 & .00 & & \\
\hline Avg. No. Team Memberships $\times$ Patient Case Complexity & & & & & & & $.06^{*}$ & .02 \\
\hline \multicolumn{9}{|l|}{ Model fit } \\
\hline $2 \times \log$-likelihood & \multicolumn{2}{|c|}{$-12,432.77$} & \multicolumn{2}{|c|}{$-12,428.45$} & \multicolumn{2}{|c|}{$-12,428.38$} & \multicolumn{2}{|c|}{$-12,422.61$} \\
\hline AIC & \multicolumn{2}{|c|}{12,445} & \multicolumn{2}{|c|}{12,442} & \multicolumn{2}{|c|}{12,444} & \multicolumn{2}{|c|}{12,439} \\
\hline
\end{tabular}

Note. $\quad N=849$ primary care units. All models are adjusted for size of patient population by including the natural log of the unit's number of patients as an offset variable with a coefficient fixed at 1 . Higher numbers of emergency department visits indicate worse performing units. Positive coefficients indicate an increased likelihood of emergency department visits, whereas negative coefficients indicate a decreased likelihood of emergency department visits. Avg. = average; $\mathrm{AIC}=$ Akaike information criterion.

${ }^{\mathrm{a}}$ Due to large differences in range, this variable has been standardized. ${ }^{\mathrm{b}}$ Coded as 1 (urban) and 0 (rural).

${ }^{*} p<.05$. 


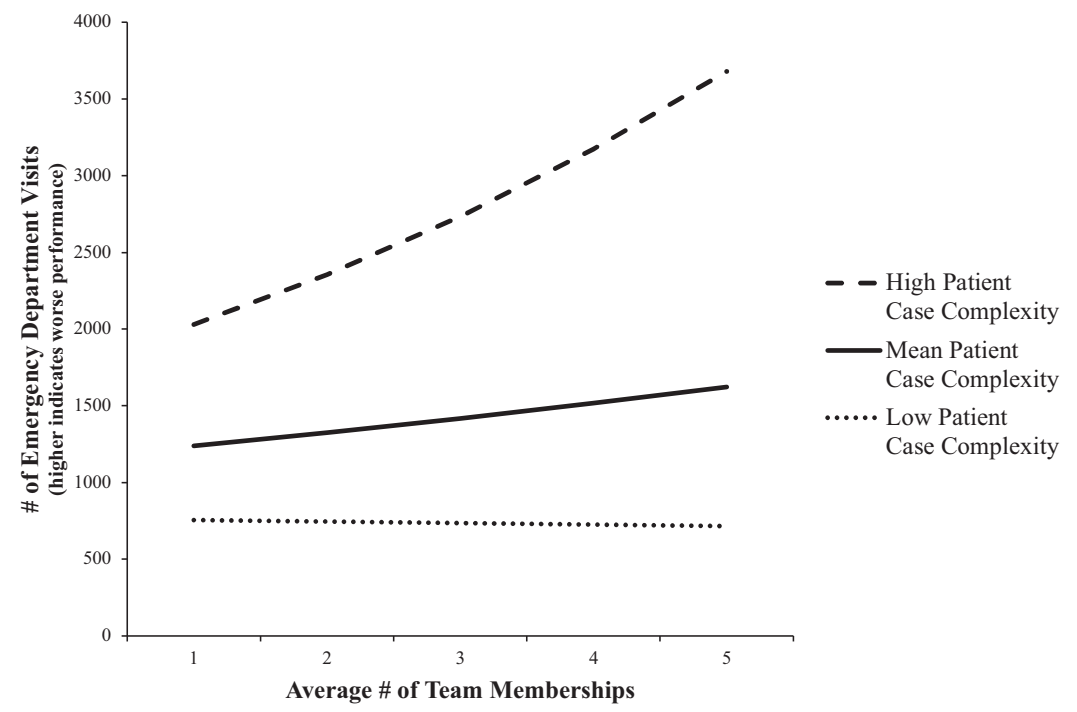

Figure 2. Multiple team membership and patient case complexity interaction predicting emergency department use. Predicted numbers of emergency department visits are derived by first exponentiating the sum of model coefficients multiplied by relevant variable values, then multiplying the result by the average number of primary care unit patients. The resulting values represent the expected number of emergency department visits per unit at varying levels of patient case complexity and multiple team membership. Values of patient case complexity were set at the mean, $+1 S D$, and $-1 S D$. Values of multiple team memberships were set at levels corresponding to $1,2,3,4$, and 5 memberships, a range that includes the actual values observed in $99.4 \%$ of all primary care units in the data set. Higher numbers of emergency department visits indicate worse performance.

relevant range of data, is expected to result in approximately 384 additional emergency department visits per year (a $31 \%$ increase).

For a unit with high patient case complexity $(+1 S D)$, our model estimated that the predicted emergency department use when all caregivers are assigned to only one team is approximately 2,030 visits per year. Note that this higher number, compared to that of average patient case complexity, illustrates the strong main effect of medical complexity on emergency department use. An increase of just one team membership per person is expected to result in approximately 325 additional emergency department visits per year (a 16\% increase). An increase of two team memberships per person is expected to result in approximately 703 additional emergency department visits per year (a 35\% increase). An increase to five team memberships per person is expected to result in approximately 1,649 additional emergency department visits per year (an $81 \%$ increase).

To illustrate these effects in dollar terms, the Congressional Budget Office (2014) estimated that each VHA emergency department visit costs $\$ 1,122$ on average. The mean number of team memberships per person across all primary care units of the VHA is 1.44. Again, holding the number of patients, staffing levels, and unit locations constant, if all primary care units were to move to one team membership per person from the average of 1.44 , the VHA-wide expected reduction in the number of emergency department visits per year would be approximately 31,730 fewer visits per year. In dollar terms, this equates to a reduction in emergency department costs of approximately $\$ 35.6$ million per year. In contrast, if all primary care units were to move to two team memberships per person from the average of 1.44, the VHA-wide expected increase in the number of emergency department visits per year would be approximately 41,772 more visits per year. In dollar terms, this equates to an increase in emergency department costs of approximately $\$ 46.9$ million per year.

\section{Discussion}

Our results suggest that many organizations should reconsider the prevalent practice of assigning individuals to more than one team. In contrast to the recent emphasis on multiteam systems that by their very nature require coordination between teams (Mathieu et al., 2018), our study is situated in an alternative context where hierarchically independent teams are designed to internally possess requisite knowledge and skill. In particular, our data from 849 VHA primary care units revealed a negative relationship between multiple team membership and unit performance, and the negative effect was most pronounced for teams with complex work tasks. This conclusion, based on the first empirical field examination of multiple team membership at the unit level, aligns with criticisms and warnings that O'Leary and colleagues (2012) identified as existing in the practice literature over a decade ago. Specifically, DeMarco (2002, p. 20) suggested that individuals assigned to multiple teams "may look busy, but a lot of their busyness is just thrashing." More directly, Shore and Warden (2007) claimed:

Some organizations like to assign people to multiple teams simultaneously. ... If your company practices [this] fractional assignment, I have some good news. You can instantly improve productivity by reassigning people to only one project at a time. Fractional assignment is dreadfully counterproductive: fractional workers do not bond with their teams, they often aren't around to hear 
conversations and answer questions, and they must task switch, which incurs a significant hidden penalty. (p. 39)

Our abductive process of discovery thus extended previous multiple team membership research conducted at the individual and team levels to the unit level of analysis and demonstrates the necessity of clarifying how individual and team effects combine with between-team interactions to influence higher-level collective effectiveness across teams. Although our description of the iterative process of observation, literature search, and theory development is somewhat different from the traditional deductive method of beginning with clearly developed theory, we believe it more accurately reflects what actually occurs as research unfolds in complex organizations. Not only does this process of starting with the observation of an organizational phenomenon guard against conducting research based on interesting but obscure theory that risks failure to provide practical application for improving organizations (Mathieu, 2016; Spector, 2017), but given that we began with a practice-based expectation for the detrimental effects of team member sharing, it also guards against hypothesizing after results are known (HARKing; Hollenbeck \& Wright, 2017; Kerr, 1998). We hope our description of the process of inquiry as it unfolded provides a template for future reporting of abductive research.

\section{Implications for Theory}

As pointed out by Tannenbaum and colleagues (2012), multiple team membership is a poorly understood feature of team-based organizational structures. Our examination of the collective effects of multiple team membership, which goes beyond previous work at the individual and team levels, is a critical extension because by its very nature multiple team membership has an effect that transcends any given team and must therefore be examined across levels and among teams. Our examination of multiple team membership at the unit level provides theoretical direction in three specific ways.

The first theoretical implication is that efforts to understand team-based organizational structure should account for the interplay of within- and between-team coordination. Working from the organizational structure principle of hierarchical decomposition, we developed the general expectation that coordination is most beneficial when it occurs at the lowest possible level within a nested structure: first within individuals, next within teams, and finally between teams. This explication of levels at which work is coordinated has important-yet to date mostly unexploredimplications for the structuring of organizational units that include more than a single team. One option, which is advanced by the multiteam systems literature (Firth et al., 2015; Mathieu et al., 2018), is to have component teams specialize in specific tasks that are then coordinated through between-team linkages. The contrasting option that we explicate in this study is to design hierarchically autonomous teams that contain the necessary skills and resources to complete work (Manz \& Stewart, 1997). These teams benefit from extensive within-team coordination, which is often impaired by effort expended toward between-team coordination. The differential value of within-team coordination and between-team coordination is thus a critical factor to account for when theorizing about how work tasks should be structured for team-based units and systems. Work that cannot be completed within a single team should be structured with an emphasis on coordinating tasks between teams, whereas work that can be accomplished within a single team should emphasize relationships and synchronization within teams while eschewing the encumbrances associated with between-team coordination.

The second theoretical implication relates specifically to multiple team membership. Theoretical perspectives emerging from the individual and group levels have suggested optimal levels of multiple team membership occur with individuals belonging to somewhere between three (O'Leary et al., 2011) and nine teams (Bertolotti et al., 2015). In contrast, our theoretical perspective, grounded in microfoundations and organization structure thinking, suggests that in certain contexts any increase in multiple team membership may be harmful. In organizations such as the VHA, where teams are hierarchically independent (i.e., goal attainment is not highly interdependent with other entities nested within the higher level), collective performance of organizational units is often harmed by efforts to increase between-team coordination, suggesting that even minimal sharing of members across teams is detrimental. Additional insight into the contexts in which multiple team membership is beneficial or harmful can most likely be facilitated by further applying the microfoundation lens and explicitly examining how factors such as slack time for individuals, resource-sufficiency for teams, and need for between-team coordination emerge and combine to influence units and organizations. Indeed, although individual- and team-level theory provides insight toward some of the building blocks that should be included in unit- and organization-level theory, specifically accounting for how effects at one level (e.g., expending a great deal of effort maintaining relationships with members of other teams) influence effects at a different level (e.g., developing relationships and coordinating tasks within a team) is fundamental for gaining insight into how multiple team membership operates at the unit level.

Our third theoretical implication reinforces the importance of considering the nature and complexity of tasks in investigations of multiple team membership's effects. Groups and teams researchers have long called for an enhanced focus on tasks (Kerr, 2015; McGrath, 1997), stating "which variables will 'make a difference' in measuring group effectiveness is heavily determined by the type of group task on which the group is working" (Hackman \& Morris, 1975, p. 63). More recently, in the special issue celebrating a century of research in the Journal of Applied Psychology, scholars renewed the call to "feature task characteristics more prominently than we have in the past" (Mathieu et al., 2017, p. 461). We highlight the applicability of this general observation to the unit level and illustrate the necessity of applying rationale from individual- and team-level task-complexity models when examining relationships for units comprising collectives of teams. Though multiple team membership appeared not to affect units with less complex tasks, the effects were significant for units facing average-complexity tasks and exacerbated a great deal for units facing high-complexity tasks. Our theoretical implication is that the negative effects of sharing team members becomes more pronounced when complexity further shifts the costs of multiple team membership relative to the benefits of bounded teams. Indeed, our model suggests that as member-sharing approaches four or five teams per person, emergency department use will more than double in units facing complex tasks relative to those facing 
average task complexity. Because we found task complexity to be such an important moderator, we encourage future researchers of multiple team membership relationships to account for it in their theoretical models and empirical examinations.

\section{Implications for Practice}

Our results provide direct practical implications for the provision of primary care in the hierarchically independent patientcentered medical homes of the VHA. In this context, the major implication is that allowing care givers to focus efforts in a single team would appear to be more beneficial than having them spread efforts across multiple teams. Our estimates suggest that reducing sharing of team members within primary care units by assigning nurses and administrative associates to single teams dedicated to serving the needs of a restricted group of patients to whom they provide more patient-centered care could save the VHA over $\$ 35$ million annually. This structure is the very premise of the medical home model upon which the VHA initiative was based (Bodenheimer et al., 2014; Rosland et al., 2013), and our findings provide compelling supportive evidence for this model. In contrast, diluting the ability of caregivers to focus on specific groups of patients by assigning members to an increasing number of teams-even as few as two on average-could cost the VHA over \$46 million annually. As the pattern in Figure 2 illustrates, costs associated with increases in multiple team membership appear highest for units caring for more complex patients. In contrast, the care for patients with relatively simple medical conditions appeared to suffer little from increases in multiple team membership. This suggests that unit leaders may be able to tailor multiple team membership to levels of task complexity, in which potential efficiencies generated from use of multiple team membership in conditions of low complexity may be used to support highcomplexity conditions, where the detriments of sharing team members appear more important to avoid.

Second, our results provide potential guidance for structuring and organizing work efforts for health care delivery more generally, where there is ongoing debate about the extent to which principles of work design associated with product manufacturing can be applied to improve patient care. For example, a prominent approach is commonly labeled lean, which advocates adopting the quality improvement philosophy and principles utilized by Toyota Manufacturing to organize patient services (Kim, Spahlinger, Kin, \& Billi, 2006; Toussaint \& Berry, 2013). Such an approach may be beneficial for improving health care services where work processes and inputs can be standardized, such as in some specialty surgical services. However, for services where high variance among patient diseases and lack of certainty about means-ends relationships exists, the degree of standardization and control necessary for optimization of assembly line work processes is likely impossible and calls into question the merit of applying lean principles. Fortunately, our results demonstrate how highly autonomous teams that eschew multiple team membership and adapt internally to complete complex tasks provide a promising alternative for structuring health care delivery.

Of course, cost differentials and efficiency considerations are an important part of the debate between lean manufacturing techniques and autonomous teams, which has been occurring for at the least the past 50 years (e.g., Emery \& Trist, 1969). The VHA setting, which did not seek to reduce staff count as part of multiple team membership, provided a unique setting that allowed us to examine the effect of multiple team membership holding labor cost constant. Because our approach does not directly assess costs and benefits associated with different staff counts, we are unable to speak directly to issues of labor-efficiency tradeoffs between fully staffed autonomous teams and a leaner labor structure that may include reduced head count achieved by sharing a common individual in a specific role across multiple teams. However, our findings, which are conservative because they account for sharing members across teams with a fixed head count and without including other capacity losses associated with reduced head count, are nevertheless consistent with the notion that labor force reduction often corresponds with long-term costs that come from decreased capability in preventative areas. An important practical implication of our findings is that although many organizations resort to assigning people to multiple teams to increase efficiency and reduce costs, there can be substantial hidden costs to these decisions that cannot be ignored or discounted. Organizations with team-based structures considering staff reductions through increasing multiple team membership should carefully consider the costs that may arise as remaining staff is spread more thinly across multiple teams.

Although we conducted our study in the health care industry, our results likely have implications for many other settings where the costs of coordination across teams are higher than the potential benefits of cross-team learning. For example, the costs associated with multiple team membership necessitated by staff reduction might play out as administrative assistants transition from a structure where each person works within a unique department to a structure where a smaller number of assistants are assigned across multiple departments that have little need to coordinate work between departments. Under this new multiple team membership structure, the collective productivity of administrative assistants is diminished due not only to the smaller workforce but also because each assistant must now develop and maintain relationships with a greater number of other employees. Additionally, the remaining assistants must direct a substantial amount of time to coordinating the shared work that moves back and forth between them. Finally, an example that perhaps resonates with researchers relates to the dilution of focus that comes from professors and students spreading their efforts across multiple research teams. When researchers become involved in too many research projects, they spend a majority of their time navigating switches (e.g., refamiliarizing themselves with previous work and maintaining communication) with several author teams, frequently moving from one project to the next rather than actually completing tasks such as data analysis and writing. Perhaps researchers can improve their own productivity by limiting the number of simultaneous research teams to which they belong to better focus efforts on accomplishing tasks rather than coordinating with others.

\section{Limitations and Future Directions for Research}

Our examination of 849 VHA primary care units provided a unique opportunity for studying the relationship between multiple team membership and unit performance in a field setting. There are, however, some inherent limitations of our study that provide direction for future research. First, our empirical examination was 
limited to a context of units in one umbrella health care system where work was structured around hierarchically independent teams that internally possessed the skill and knowledge necessary to complete work. This context was beneficial because it allowed us to adopt a common performance metric and extended inquiry into cross-team coordination beyond previous work focused on multiteam systems. However, we acknowledge that the effects of multiple team membership on collective performance across teams depend on the organizational context. Additional studies in other contexts, including more explicit examinations in multiteam system contexts, are warranted to better understand the extent to which our results, as well as the underlying unit-level theory of multiple team membership, are generalizable. One way to account for this would be to model the extent to which a collective system of teams shares superordinate goals and system-level cross-team task interdependence to achieve those goals. This would provide greater insight into the tradeoff in between-team coordination relative to within-team coordination.

Second, our design only provides evidence of association between multiple team membership and unit performance rather than causation, because we were not in a position to manipulate team membership structure. It is possible that performance in these primary care units drives team membership assignments. At a minimum, where field experiments are not possible, future research incorporating cross-lagged longitudinal designs tracking changes in multiple team membership and unit performance over time will be necessary to increase confidence regarding the causal direction of relationships. We are also unable to explain why units differed in their levels of multiple team membership. Although we accounted for staffing resources and geographic location of primary care units in our models, future research should examine other factors that might explain the origins of multiple team membership.

Third, the average number of team memberships per person observed across all primary care units in our study is low $(M=$ 1.44 team memberships per person, $S D=.74)$. This suggests that our observed relationships are likely attenuated because a majority of primary care units' average number of team memberships is between one and two, even though the relevant range extends to units with five or more team memberships per person on average. Given this potential attenuation, our results can be viewed as conservative, suggesting that the practical effects presented earlier may be underestimated. Future unit-level research that can observe a wider distribution of multiple team membership will be useful to improve estimates of the relationship between multiple team membership and unit performance.

Fourth, our theorizing references mechanisms such as switching costs and decreased team cohesion, through which multiple team membership affects unit performance. These mechanisms are mainly reflected in the tension concerning the balance of within-team coordination and between-team coordination. Unfortunately, the VHA's archived records did not provide measures of these mechanisms, nor could we obtain these measures via surveys or observations. Although we relied on the application of prior individual- and team-level studies suggesting these are relevant mechanisms, further empirical research is necessary to explicitly model the processes through which multiple team membership influences collective performance across teams. Doing so will require researchers to simultaneously capture the experiences and perceptions of individuals assigned to multiple teams and the team members who interact with them along with unit-level performance metrics.

Finally, although we examined task complexity as a moderator, it is possible that other factors alter the relationship between multiple team membership and unit performance. For example, multiple team membership's disruption of unit performance may be changed by the tenure of members who work on multiple teams, as well as by the turnover rates of personnel in the units in which those members are embedded. Multiple team membership may be more disruptive in a unit whose members change frequently because of the difficulty for new members to form cohesive relationships with members of so many other teams. In contrast, multiple team membership may be less disruptive for units of long-tenured members who have developed significant shared histories that enable efficient use of limited time working together. Multiple team membership may itself have implications for the relationship between unit turnover rates and unit performance (cf. Reilly et al., 2014). For example, the effects of turnover on a broad system may be enhanced when those who depart belong to a larger number of teams. Exploring the interplay between a potentially greater breadth of impact of turnover across teams and a potentially shallower depth of impact within teams could yield valuable insights for organizational design efforts.

\section{Conclusion}

Tannenbaum and colleagues (2012) advocated for additional research exploring the implications of individuals working in multiple teams for individual well-being, team effectiveness, and collective effectiveness across teams. Our study of the VHA's primary care units provides initial empirical evidence that collective performance across teams is lower when individuals are assigned to multiple teams. This negative relationship is exacerbated when task complexity increases. Organizations may adopt multiple team membership in the hopes of leveraging scarce resources effectively. However, our evidence suggests multiple team membership may actually be more costly in contexts where there is little benefit from betweenteam coordination.

\section{References}

Aguinis, H., \& Vandenberg, R. J. (2014). An ounce of prevention is worth a pound of cure: Improving research quality before data collection. Annual Review of Organizational Psychology and Organizational Behavior, 1, 569-595. http://dx.doi.org/10.1146/annurev-orgpsych-031413-091231

Allison, P. D. (1999). Logistic regression using SAS: Theory and application. Cary, NC: SAS Institute.

American Academy of Family Physicians. (2008). Joint principles of the patient-centered medical home. Delaware Medical Journal, 80, 21-22.

Ancona, D. G. (1990). Outward bound: Strategies for team survival in an organization. Academy of Management Journal, 33, 334-365. http://dx .doi.org/10.5465/256328

Ancona, D. G., \& Caldwell, D. F. (1992). Demography and design: Predictors of new product team performance. Organization Science, 3, 321-341. http://dx.doi.org/10.1287/orsc.3.3.321

Argote, L., \& Todorova, G. (2007). Organizational learning. International Review of Industrial and Organizational Psychology, 22, 193-234.

Barney, J., \& Felin, T. (2013). What are microfoundations? Academy of Management Perspectives, 27, 138-155. http://dx.doi.org/10.5465/amp .2012 .0107

Bertolotti, F., Mattarelli, E., Vignoli, M., \& Macrì, D. M. (2015). Exploring the relationship between multiple team membership and team perfor- 
mance: The role of social networks and collaborative technology. Research Policy, 44, 911-924. http://dx.doi.org/10.1016/j.respol.2015.01 .019

Bodenheimer, T., Ghorob, A., Willard-Grace, R., \& Grumbach, K. (2014). The 10 building blocks of high-performing primary care. Annals of Family Medicine, 12, 166-171. http://dx.doi.org/10.1370/afm.1616

Brousseau, D. C., Hoffmann, R. G., Nattinger, A. B., Flores, G., Zhang, Y., $\&$ Gorelick, M. (2007). Quality of primary care and subsequent pediatric emergency department utilization. Pediatrics, 119, 1131-1138. http://dx .doi.org/10.1542/peds.2006-3518

Burns, T. E., \& Stalker, G. M. (1961). The management of innovation. London, UK: Tavistock.

Cohen, S. G., \& Bailey, D. E. (1997). What makes teams work: Group effectiveness research from the shop floor to the executive suite. Journal of Management, 23, 239-290. http://dx.doi.org/10.1177/01492063 9702300303

Congressional Budget Office. (2014). Comparing the costs of the Veterans' Health Care system with private-sector costs. Retrieved from https:// www.cbo.gov/sites/default/files/113th-congress-2013-2014/reports/ 49763-VA_Healthcare_Costs.pdf

Coxe, S., West, S. G., \& Aiken, L. S. (2009). The analysis of count data: A gentle introduction to Poisson regression and its alternatives. Journal of Personality Assessment, 91, 121-136. http://dx.doi.org/10.1080/002 23890802634175

Cummings, J. N., \& Haas, M. R. (2012). So many teams, so little time: Time allocation matters in geographically dispersed teams. Journal of Organizational Behavior, 33, 316-341. http://dx.doi.org/10.1002/job.777

Davison, R. B., Hollenbeck, J. R., Barnes, C. M., Sleesman, D. J., \& Ilgen, D. R. (2012). Coordinated action in multiteam systems. Journal of Applied Psychology, 97, 808-824. http://dx.doi.org/10.1037/a0026682

Dawson, J. F. (2014). Moderation in management research: What, why, when, and how. Journal of Business and Psychology, 29, 1-19. http:// dx.doi.org/10.1007/s10869-013-9308-7

DeMarco, T. (2002). Slack: Getting past burnout, busywork, and the myth of total efficiency. New York, NY: Broadway Books.

de Vries, T. A., Walter, F., Van der Vegt, G. S., \& Essens, P. J. (2014). Antecedents of individuals' interteam coordination: Broad functional experiences as a mixed blessing. Academy of Management Journal, 57, 1334-1359. http://dx.doi.org/10.5465/amj.2012.0360

Ellis, R. P., \& Ash, A. (1995). Refinements to the diagnostic cost group (DCG) model. Inquiry: The Journal of Health Care Organization, Provision, and Financing, 32, 418-429.

Emery, F. E., \& Trist, E. L. (1969). The causal texture of organizational environments. Systems Thinker, 1, 245-262.

Espinosa, J. A., Cummings, J. N., Wilson, J. M., \& Pearce, B. M. (2003). Team boundary issues across multiple global firms. Journal of Management Information Systems, 19, 157-190. http://dx.doi.org/10.1080/074 21222.2003.11045746

Felin, T., Foss, N. J., \& Ployhart, R. E. (2015). The microfoundations movement in strategy and organization theory. Academy of Management Annals, 9, 575-632. http://dx.doi.org/10.5465/19416520.2015.1007651

Firth, B. M., Hollenbeck, J. R., Miles, J. E., Ilgen, D. R., \& Barnes, C. M. (2015). Same page, different books: Extending representational gaps theory to enhance performance in multiteam systems. Academy of Management Journal, 58, 813-835. http://dx.doi.org/10.5465/amj.2013.0216

Flores-Mateo, G., Violan-Fors, C., Carrillo-Santisteve, P., Peiró, S., \& Argimon, J. M. (2012). Effectiveness of organizational interventions to reduce emergency department utilization: A systematic review. PLoS ONE, 7(5), e35903. http://dx.doi.org/10.1371/journal.pone.0035903

Gardner, W., Mulvey, E. P., \& Shaw, E. C. (1995). Regression analyses of counts and rates: Poisson, overdispersed Poisson, and negative binomial models. Psychological Bulletin, 118, 392-404. http://dx.doi.org/10.1037/ 0033-2909.118.3.392
Gladstein, D. L. (1984). Groups in context: A model of task group effectiveness. Administrative Science Quarterly, 29, 499-517. http://dx.doi .org/10.2307/2392936

Guagliardo, M., Flemming, D., Gatlin, C., Skupien, M. B., Golterman, L., Benson, G., \& Dunlow, S. A. (2013). VHA rurality definitions and methods work group report [VHA internal report]. Seattle, WA: Department of Veterans Affairs.

Hackman, J. R. (1987). The design of work teams. In J. W. Lorsch (Ed.), Handbook of Organizational Behavior (pp. 315-342). Englewood Cliffs, NJ: Prentice-Hall.

Hackman, J., \& Morris, C. (1975). Group tasks, group interaction process and group performance effectiveness: A review and proposed integration. In L. Berkowitz (Ed.), Advances in experimental social psychology (Vol. 8, pp. 45-99). New York, NY: Academic Press. http://dx.doi.org/ 10.1016/S0065-2601(08)60248-8

Hambrick, D. C. (2007). The field of management's devotion to theory: Too much of a good thing? Academy of Management Journal, 50, 1346-1352. http://dx.doi.org/10.5465/amj.2007.28166119

Hansen, M. T. (1999). The search-transfer problem: The role of weak ties in sharing knowledge across organization subunits. Administrative Science Quarterly, 44, 82-111. http://dx.doi.org/10.2307/2667032

Harter, J. K., Schmidt, F. L., \& Hayes, T. L. (2002). Business-unit-level relationship between employee satisfaction, employee engagement, and business outcomes: A meta-analysis. Journal of Applied Psychology, 87, 268-279. http://dx.doi.org/10.1037/0021-9010.87.2.268

Hausknecht, J. P., Hiller, N. J., \& Vance, R. J. (2008). Work-unit absenteeism: Effects of satisfaction, commitment, labor market conditions, and time. Academy of Management Journal, 51, 1223-1245. http://dx doi.org/10.5465/amj.2008.35733022

Hausknecht, J. P., \& Trevor, C. O. (2011). Collective turnover at the group, unit, and organizational levels: Evidence, issues, and implications. Journal of Management, 37, 352-388. http://dx.doi.org/10.1177/01492 06310383910

Hollenbeck, J. R., Beersma, B., \& Schouten, M. E. (2012). Beyond team types and taxonomies: A dimensional scaling conceptualization for team description. Academy of Management Review, 31, 82-106.

Hollenbeck, J. R., \& Wright, P. M. (2017). Harking, sharking, and tharking: Making the case for post hoc analysis of scientific data. Journal of Management, 43, 5-18. http://dx.doi.org/10.1177/0149206316679487

Ionescu-Ittu, R., McCusker, J., Ciampi, A., Vadeboncoeur, A. M., Roberge, D., Larouche, D., . . . Pineault, R. (2007). Continuity of primary care and emergency department utilization among elderly people. Canadian Medical Association Journal, 177, 1362-1368. http://dx .doi.org/10.1503/cmaj.061615

Islam, R., Weir, C., \& Del Fiol, G. (2016). Clinical complexity in medicine: A measurement model of task and patient complexity. Methods of Information in Medicine, 55, 14-22. http://dx.doi.org/10.3414/ME1501-0031

Johns, G. (2006). The essential impact of context on organizational behavior. Academy of Management Review, 31, 386-408. http://dx.doi.org/ 10.5465/amr.2006.20208687

Johnson, V., Wong, E., Lampman, M., Curtis, I., Fortney, J., Kaboli, P., . . Nelson, K. (2018). Comparing patient-centered medical home implementation in urban and rural VHA clinics: Results from the Patient Aligned Care Team initiative. Journal of Ambulatory Care Management, 41, 47-57. http://dx.doi.org/10.1097/JAC.0000000000000212

Joo, H., Aguinis, H., \& Bradley, K. J. (2017). Not all nonnormal distributions are created equal: Improved theoretical and measurement precision. Journal of Applied Psychology, 102, 1022-1053. http://dx.doi.org/ 10.1037/ap10000214

Katz, N., Lazer, D., Arrow, H., \& Contractor, N. (2004). Network theory and small groups. Small Group Research, 35, 307-332. http://dx.doi.org/ $10.1177 / 1046496404264941$ 
Kc, D. S., \& Terwiesch, C. (2009). Impact of workload on service time and patient safety: An econometric analysis of hospital operations. Management Science, 55, 1486-1498. http://dx.doi.org/10.1287/mnsc.1090.1037

Kerr, N. L. (1998). HARKing: Hypothesizing after the results are known. Personality and Social Psychology Review, 2, 196-217. http://dx.doi .org/10.1207/s15327957pspr0203_4

Kerr, N. L. (2015, July). The most neglected moderator in groups research. J. E. McGrath Award lecture presented at the annual INGRoup conference, Pittsburgh, PA.

Kim, C. S., Spahlinger, D. A., Kin, J. M., \& Billi, J. E. (2006). Lean health care: What can hospitals learn from a world-class automaker? Journal of Hospital Medicine, 1, 191-199. http://dx.doi.org/10.1002/jhm.68

Kozlowski, S. W., \& Ilgen, D. R. (2006). Enhancing the effectiveness of work groups and teams. Psychological Science in the Public Interest, 7 , 77-124. http://dx.doi.org/10.1111/j.1529-1006.2006.00030.x

Kozlowski, S. W. J., \& Klein, K. J. (2000). A multilevel approach to theory and research in organizations: Contextual, temporal, and emergent processes. In K. J. Klein \& S. W. J. Kozlowski (Eds.), Multilevel theory, research, and methods in organizations: Foundations, extensions, and new directions (pp. 3-90). San Francisco, CA: Jossey-Bass.

Lanaj, K., Hollenbeck, J. R., Ilgen, D. R., Barnes, C. M., \& Harmon, S. J. (2013). The double-edged sword of decentralized planning in multiteam systems. Academy of Management Journal, 56, 735-757. http://dx.doi .org/10.5465/amj.2011.0350

Leroy, S. (2009). Why is it so hard to do my work? The challenge of attention residue when switching between work tasks. Organizational Behavior and Human Decision Processes, 109, 168-181. http://dx.doi .org/10.1016/j.obhdp.2009.04.002

Lewis, K., Lange, D., \& Gillis, L. (2005). Transactive memory systems, learning, and learning transfer. Organization Science, 16, 581-598. http://dx.doi.org/10.1287/orsc. 1050.0143

Long, J. S. (1997). Regression models for categorical and limited dependent variables. Thousand Oaks, CA: Sage.

Lowe, R. A., Localio, A. R., Schwarz, D. F., Williams, S., Tuton, L. W., Maroney, S., . . Feldman, H. I. (2005). Association between primary care practice characteristics and emergency department use in a Medicaid managed care organization. Medical Care, 43, 792-800. http://dx .doi.org/10.1097/01.mlr.0000170413.60054.54

Maciejewski, M. L., Liu, C.-F., Derleth, A., McDonell, M., Anderson, S., \& Fihn, S. D. (2005). The performance of administrative and selfreported measures for risk adjustment of Veterans Affairs expenditures. Health Services Research, 40, 887-904. http://dx.doi.org/10.1111/j .1475-6773.2005.00390.x

Manz, C. C., \& Stewart, G. L. (1997). Attaining flexible stability by integrating total quality management and socio-technical systems theory. Organization Science, 8, 59-70. http://dx.doi.org/10.1287/orsc.8.1.59

March, J. G., \& Simon, H. A. (1958). Organizations. Oxford, United Kingdom: Wiley.

Mark, G., Gonzalez, V. M., \& Harris, J. (2005). No task left behind? Examining the nature of fragmented work. Proceedings of the SIGCHI Conference on Human factors in computing systems (pp. 321-330). New York, NY: ACM.

Marks, M. A., DeChurch, L. A., Mathieu, J. E., Panzer, F. J., \& Alonso, A. (2005). Teamwork in multiteam systems. Journal of Applied Psychology, 90, 964-971. http://dx.doi.org/10.1037/0021-9010.90.5.964

Martin, A., \& Bal, V. (2015). The state of teams [White paper]. Retrieved from https://www.ccl.org/wp-content/uploads/2015/04/StateOfTeams .pdf

Mathieu, J. E. (2016). The problem with [in] management theory. Journal of Organizational Behavior, 37, 1132-1141. http://dx.doi.org/10.1002/ job.2114

Mathieu, J. E., Hollenbeck, J. R., van Knippenberg, D., \& Ilgen, D. R. (2017). A century of work teams in the Journal of Applied Psychology.
Journal of Applied Psychology, 102, 452-467. http://dx.doi.org/10 .1037/ap10000128

Mathieu, J. E., Luciano, M. M., \& DeChurch, L. A. (2018). Multiteam systems: The next chapter. In D. S. Ones, N. Anderson, C. Viswesvaran, \& H. K. Sinangil (Eds.), The Sage handbook of industrial, work, \& organizational psychology (2nd ed., pp. 333-353). London, UK: Sage.

Mathieu, J. E., Marks, M. A., \& Zaccaro, S. J. (2001). Multiteam systems. In N. Anderson, D. S. Ones, J. K. Sinangil, \& C. Viswesvaran (Eds.), Organizational psychology: Handbook of industrial, work and organizational psychology (Vol. 2, pp. 289-313). London, UK: Sage. http:// dx.doi.org/10.4135/9781848608368.n16

Maynard, M. T., Mathieu, J. E., Rapp, T. L., \& Gilson, L. L. (2012). Something(s) old and something(s) new: Modeling drivers of global virtual team effectiveness. Journal of Organizational Behavior, 33, 342-365. http://dx.doi.org/10.1002/job.1772

Maznevski, M. L., \& Chudoba, K. M. (2000). Bridging space over time: Global virtual team dynamics and effectiveness. Organization Science, 11, 473-492. http://dx.doi.org/10.1287/orsc.11.5.473.15200

McCaig, L. F. (1994). National Hospital Ambulatory Medical Care Survey: 1992 emergency department summary (DHHS Publication No. PHS 94-1250). Washington, DC: Government Printing Office.

McGrath, J. E. (1984). Groups: Interaction and performance (Vol. 14). Englewood Cliffs, NJ: Prentice Hall.

McGrath, J. (1997). Small group research, that once and future field: An interpretation of the past with an eye to the future. Group Dynamics: Theory, Research, and Practice, 1, 7-27. http://dx.doi.org/10.1037/10892699.1.1.7

Milgrom, P. R., \& Roberts, J. D. (1992). Economics, organization and management. Englewood Cliffs, NJ: Prentice Hall.

Miller, C. C., Glick, W. H., Wang, Y.-D., \& Huber, G. P. (1991). Understanding technology-structure relationships: Theory development and metaanalytic theory testing. Academy of Management Journal, 34, 370-399.

Morgan, P., Everett, C. M., Smith, V. A., Woolson, S., Edelman, D., Hendrix, C. C., ... Jackson, G. L. (2017). Factors associated with having a physician, nurse practitioner, or physician assistant as primary care provider for veterans with diabetes mellitus. Inquiry: The Journal of Health Care Organization, Provision, and Financing, 54. http://dx.doi .org/10.1177/0046958017712762

Morgan, S. R., Chang, A. M., Alqatari, M., \& Pines, J. M. (2013). Non-emergency department interventions to reduce ED utilization: A systematic review. Academic Emergency Medicine, 20, 969-985. http:// dx.doi.org/10.1111/acem.12219

Mortensen, M. (2014). Constructing the team: The antecedents and effects of membership model divergence. Organization Science, 25, 909-931. http://dx.doi.org/10.1287/orsc.2013.0881

National Committee for Quality Assurance. (2013). Patient-centered medical home recognition. Retrieved from http://www.ncqa.org/Programs/ Recognition/Practices/PatientCenteredMedicalHomePCMH.aspx

O’Leary, M. B., Mortensen, M., \& Woolley, A. W. (2011). Multiple team membership: A theoretical model of its effects on productivity and learning for individuals and teams. Academy of Management Review, 36, $461-478$.

O'Leary, M. B., Woolley, A. W., \& Mortensen, M. (2012). Multiteam membership in relation to multiteam systems. In S. J. Zaccaro, M. A. Marks, \& L. A. DeChurch (Eds.), Multiteam systems: An organization form for dynamic and complex environments (pp. 141-172). New York, NY: Routledge.

Pluut, H., Flestea, A. M., \& Curşeu, P. L. (2014). Multiple team membership: A demand or resource for employees? Group Dynamics: Theory, Research, and Practice, 18, 333-348. http://dx.doi.org/10.1037/gdn0000016

Pope, G. C., Ellis, R. P., Ash, A. S., Ayanian, J. Z., Bates, D. W., Burstin, H., ... Wu, B. (2000). Diagnostic cost group hierarchical condition models for Medicare risk adjustment (HCFA Contract No. 500-95-048). Retrieved 
from https://www.cms.gov/Research-Statistics-Data-and-Systems/ Statistics-Trends-and-Reports/Reports/downloads/pope_2000_2.pdf

R Core Team. (2016). R: A language and environment for statistical computing [Computer software]. Retrieved from https://www.R-project .org/

Reilly, G., Nyberg, A. J., Maltarich, M., \& Weller, I. (2014). Human capital flows: Using context-emergent turnover (CET) theory to explore the process by which turnover, hiring, and job demands affect patient satisfaction. Academy of Management Journal, 57, 766-790. http://dx .doi.org/10.5465/amj.2012.0132

Rosland, A.-M., Nelson, K., Sun, H., Dolan, E. D., Maynard, C., Bryson, C., ... Schectman, G. (2013). The patient-centered medical home in the Veterans Health Administration. American Journal of Managed Care, 19, e263-e272.

Rui, P., \& Kang, K. (2015). National Hospital Ambulatory Medical Care Survey: 2015 emergency department summary tables. Retrieved from http://www.cdc.gov/nchs/data/ahcd/nhamcs_emergency/2015_ed_ web_tables.pdf

Schultz, M. (1991). Transitions between symbolic domains in organizations. Organization Studies, 12, 489-506. http://dx.doi.org/10.1177/017 084069101200402

Shore, J., \& Warden, S. (2007). Art of agile development. Sebastopol, CA: O'Reilly Media.

Sinha, K. K., \& Van de Ven, A. H. (2005). Designing work within and between organizations. Organization Science, 16, 389-408. http://dx .doi.org/10.1287/orsc. 1050.0130

Solimeo, S. L., Hein, M., Paez, M., Ono, S., Lampman, M., \& Stewart, G. L. (2013). Medical homes require more than an EMR and aligned incentives. American Journal of Managed Care, 19, 132-140.

Spector, P. E. (2017). The lost art of discovery: The case for inductive methods in occupational health science and the broader organizational sciences. Occupational Health Science, 1(1-2), 11-27. http://dx.doi.org/ 10.1007/s41542-017-0001-5

Staats, B. R., Gino, F., \& Pisano, G. P. (2010). Varied experience, team familiarity, and learning: The mediating role of psychological safety (Harvard Business School Working Paper No. 10-016). Boston, MA: Harvard Business School.

Stewart, G. L., Astrove, S. L., Reeves, C. J., Crawford, E. R., \& Solimeo, S. L. (2017). Those with the most find it hardest to share: Exploring leader resistance to the implementation of team-based empowerment. Academy of Management Journal, 60, 2266-2293. http://dx.doi.org/10 .5465/amj.2015.1173
Sundstrom, E., McIntyre, M., Halfhill, T., \& Richards, H. (2000). Work groups: From the Hawthorne studies to work teams of the 1990s and beyond. Group Dynamics: Theory, Research, and Practice, 4, 44-67. http://dx.doi.org/10.1037/1089-2699.4.1.44

Tannenbaum, S. I., Mathieu, J. E., Salas, E., \& Cohen, D. (2012). Teams are changing: Are research and practice evolving fast enough? Industrial and Organizational Psychology: Perspectives on Science and Practice, 5, 2-24. http://dx.doi.org/10.1111/j.1754-9434.2011.01396.x

Thompson, J. D. (1967). Organizations in action: Social science bases of administrative theory. New York, NY: McGraw-Hill.

Toussaint, J. S., \& Berry, L. L. (2013). The promise of lean in health care Mayo Clinic Proceedings, 88, 74-82. http://dx.doi.org/10.1016/j .mayocp.2012.07.025

Tushman, M. L., \& Nadler, D. A. (1978). Information processing as an integrating concept in organizational design. Academy of Management Review, 3, 613-624.

Van de Ven, A. H., \& Delbecq, A. L. (1974). A task contingent model of work-unit structure. Administrative Science Quarterly, 19, 183-197. http://dx.doi.org/10.2307/2393888

Van de Ven, A. H., Delbecq, A. L., \& Koenig, R., Jr. (1976). Determinants of coordination modes within organizations. American Sociological Review, 41, 322-338. http://dx.doi.org/10.2307/2094477

Wilson, J. M., Goodman, P. S., \& Cronin, M. A. (2007). Group learning. Academy of Management Review, 32, 1041-1059. http://dx.doi.org/10 5465/amr.2007.26585724

Wood, R. E. (1986). Task complexity: Definition of the construct. Organizational Behavior and Human Decision Processes, 37, 60-82. http:// dx.doi.org/10.1016/0749-5978(86)90044-0

Zaccaro, S. J., Marks, M. A., \& DeChurch, L. A. (2012). A theory and taxonomy of multiteam systems. In S. J. Zaccaro, M. A. Marks, \& L. A. DeChurch (Eds.), Multiteam systems: An organizational form for $d y$ namic and complex environments (pp. 3-33). New York, NY: Routledge. http://dx.doi.org/10.4324/9780203814772

Zika-Viktorsson, A., Sundström, P., \& Engwall, M. (2006). Project overload: An exploratory study of work and management in multi-project settings. International Journal of Project Management, 24, 385-394. http://dx.doi.org/10.1016/j.ijproman.2006.02.010 